\title{
As relações amorosas de jovens manauenses no aplicativo de namoro Tinder
}

\author{
The loving relationships of young users from Manaus city of the dating app Tinder \\ Las relaciones amorosas de jóvenes manauenses en la aplicación de enamoramiento Tinder
}

Recebido: 01/10/2021 | Revisado: 08/10/2021 | Aceito: 12/10/2021 | Publicado: 14/10/2021

\author{
Karolayne Rodrigues Silva \\ ORCID: https://orcid.org/0000-0001-7074-3967 \\ Centro Universitário FAMETRO, Brasil \\ E-mail: karol_gois@live.com \\ Rebeca Dávila de Andrade Serejo \\ ORCID: https://orcid.org/0000-0003-2092-0528 \\ Centro Universitário FAMETRO, Brasil \\ E-mail: becadserejo@gmail.com \\ Giovanna Beatriz Dutra de Souza \\ ORCID: https://orcid.org/0000-0001-6747-3265 \\ Centro Universitário FAMETRO, Brasil \\ E-mail: beatrizgio19@gmail.com \\ Júlio César Pinto de Souza \\ ORCID: https://orcid.org/0000-0003-3622-1393 \\ Centro Universitario FAMETRO, Brasil \\ E-mail: cmte01@yahoo.com.br
}

\begin{abstract}
Resumo
As redes sociais e aplicativos existentes no mercado, vem oferecendo maior proximidade e facilidade de comunicação entre as pessoas. Em 2013, surgiu no Brasil uma ferramenta para relacionamentos amorosos a qual conseguia conectar pessoas de todos os lugares do mundo, tornando-se muito popular, principalmente entre os jovens. Essas relações virtuais possuem características muito próprias o que desperta questões afetivas e sociais tanto para quem vive a relação quanto para os observadores. Para debater o assunto, estabeleceu-se como objetivo desta pesquisa compreender o que leva os jovens manauenses a terem relações amorosas por meio do aplicativo de namoro Tinder. Esta investigação teve uma abordagem quantitativo-qualitativa, cunho descritivo e de campo. Como instrumento de pesquisa foi utilizado um questionário com perguntas abertas e fechadas, aplicado por meio do Google Forms para 30 jovens na faixa etária dos 18 a 24 anos. Como resultados foram levantados que os jovens possuem uma tendência a utilizar tal ferramenta, pois possibilita uma comunicação mais fácil, e também permite conhecer pessoas com gostos em comuns. Além disso, foram identificados que a maioria dos usuários do Tinder são indivíduos que se descrevem como extrovertidos, e que não conseguem manter relacionamentos duradouros fora do contexto virtual, devido a insegurança e a ideação de um relacionamento perfeito. Os resultados apontam que as conversas entre os usuários do Tinder costumam durar alguns meses, limitando-se apenas nas relações virtuais.
\end{abstract}

Palavras-chave: Redes sociais; Relacionamentos amorosos; Tinder; Jovens; Relações virtuais.

\begin{abstract}
Social networks and applications on the market have been offering greater proximity and ease of communication between people. In 2013, a tool for love relationships emerged in Brazil which managed to connect people from all over the world, becoming very popular, especially among young people. These virtual relationships have very unique characteristics, which arouse emotional and social issues both for those who live in the relationship and for the observers. To debate the subject, the objective of this research was to understand what leads young people from Manaus to have romantic relationships through the dating app Tinder. This investigation had a quantitative-qualitative, descriptive and field approach. As a research instrument, a questionnaire with open and closed questions was used, applied through Google Forms to 30 young people aged 18 to 24 years. As a result, it was found that young people have a tendency to use this tool, as it allows for easier communication, and also allows meeting people with common tastes. Furthermore, it was identified that the majority of Tinder users are individuals who describe themselves as extroverts, and who cannot maintain lasting relationships outside the virtual context, due to insecurity and the idea of a perfect relationship. The results show that conversations between Tinder users usually last a few months, being limited only to virtual relationships.
\end{abstract}

Keywords: Social networks; Loving relationships; Tinder; Young people; Virtual relationships.

\section{Resumen}

Las redes sociales y las aplicaciones del mercado vienen ofreciendo una mayor proximidad y facilidad de comunicación entre las personas. En 2013, surgió en Brasil una herramienta para las relaciones amorosas que logró conectar a personas de todo el mundo, volviéndose muy popular, especialmente entre los jóvenes. Estas relaciones virtuales tienen características muy singulares, que despiertan problemas emocionales y sociales tanto para quienes viven en la relación como para los 
observadores. Para debatir el tema, el objetivo de esta investigación fue comprender qué lleva a los jóvenes de Manaos a tener relaciones sentimentales a través de la aplicación de citas Tinder. Esta investigación tuvo un enfoque cuantitativo-cualitativo, descriptivo y de campo. Como instrumento de investigación se utilizó un cuestionario con preguntas abiertas y cerradas, aplicado a través de Google Forms a 30 jóvenes de entre 18 y 24 años. Como resultado, se encontró que los jóvenes tienen una tendencia a utilizar esta herramienta, ya que permite una comunicación más fácil y también permite conocer personas con gustos comunes. Además, se identificó que la mayoría de los usuarios de Tinder son personas que se describen a sí mismas como extrovertidas y que no pueden mantener relaciones duraderas fuera del contexto virtual, debido a la inseguridad y la idea de una relación perfecta. Los resultados muestran que las conversaciones entre usuarios de Tinder suelen durar unos meses, limitándose únicamente a las relaciones virtuales.

Palabras clave: Redes sociales; Relaciones amorosas; Tinder; Joven; Relaciones virtuales.

\section{Introdução}

$\mathrm{Na}$ era da tecnologia, o conceito de amor é redefinido a partir do momento em que os indivíduos estabelecem novas formas de relacionar-se, que podem iniciar e se manter somente no mundo virtual. Aplicativos de namoro não são mais novidades no contexto da sociedade moderna e possibilitam que indivíduos de lugares distantes se conheçam e se relacionem.

Dentre os aplicativos de namoro, um dos mais conhecidos e usados é o Tinder que surgiu no Brasil em 2013. Por meio deste aplicativo os indivíduos podem se conectar através de suas contas do Facebook ou por meio do número de telefone celular e e-mail. Esta ferramenta é uma espécie de cardápio humano o qual disponibiliza os perfis das pessoas, de acordo com os critérios e preferências estabelecidos pelo usuário, como a idade, localização geográfica e gênero. A partir dos perfis levantados pelo aplicativo, os usuários aprovam ou desaprovam uns aos outros (Santos, 2017).

O aplicativo torna-se um atrativo, pois é considerado a forma menos complicada de conseguir um relacionamento amoroso, afinal os relacionamentos reais ou físicos possuem riscos e geram diversos sentimentos aos indivíduos, como insegurança e medo de rejeição. Nesse sentido muitos jovens sentem-se mais seguros ao conversar virtualmente, por não ter que lidar com esses sentimentos. Outra questão que facilita os relacionamentos virtuais é a facilidade de se terminar um relação, bastando apenas apertar o botão de "desfazer amizade", ou 'deixar de seguir' que o vínculo entre os usuários se desfaz, não existindo a necessidade de encarar pessoalmente o outro (Bauman, 2004 citado por Bonavitta, 2015).

Por meio de uma leitura previa sobre o assunto, estes pesquisadores estabeleceram como problema da pesquisa o porquê dos jovens optarem pelo uso do aplicativo de namoro em detrimento das relações físicas? A partir desta discussão e com o problema norteador levantado, estabeleceu-se como objetivo primário compreender o que leva os jovens manauenses a terem relações amorosas por meio do aplicativo de namoro Tinder. Para chegar neste objetivo construiu-se um caminho metodológico onde, procurou-se, em um primeiro momento, levantou-se o perfil psicossocial desses jovens, com a proposta de que esse perfil poderia estar atrelado aos fatores do uso do aplicativo. Na sequência foi investigada a percepção dos usuários quanto aos relacionamentos virtuais que estavam ou tinham vivido, bem como os fatores que levaram esses jovens a optarem por uma relação virtual.

Os resultados desta pesquisa tornam-se relevantes, pois compreende como estes usuários se percebem e sentem ao usarem o Tinder, no qual depositam suas expectativas, que em muitos casos acaba gerando ainda mais frustração a esses jovens, devido à idealização que constroem de relacionamentos amorosos.

A relevância para a sociedade está na emissão de um alerta de como os relacionamentos estão se desenvolvendo no contexto da sociedade atual, criando vínculos frágeis e indivíduos emocionalmente carentes de afetos. De forma similar, o trabalho contribui para comunidade cientifica, visto que os profissionais da saúde mental devem estar atentos para esse tipo de mudança nas relações, buscando ações de promoção e prevenção da saúde mental do indivíduo, com ênfase aos jovens. 


\section{Metodologia}

Esta pesquisa teve uma abordagem quantitativo-qualitativa, descritiva e de campo. A pesquisa quantitativa foi utilizada a fim de, por meio da utilização da estatística, mensurar as informações obtidas em campo a partir de dados de uma determinada amostra (Cajueiro, 2013). A abordagem qualitativa foi utilizada para compreender os fenômenos, pois há um vínculo indissociável entre o mundo objetivo e a subjetividade do indivíduo que não podem ser entendidos em números (Prodanov \& Freitas, 2013). A natureza descritiva do trabalho evidencia-se pela busca da descrição das características dos eventos (Gil, 2002).

Utilizou-se como instrumento da pesquisa um questionário construído no Google Forms com quinze perguntas, sendo onze perguntas de múltipla escolha e quatro abertas. O questionário foi aplicado de forma individual, enviado por e-mail aos participantes. Para o levantamento dos participantes, os pesquisadores fizeram uma seleção prévia tendo como base a faixaetária, estado civil e local de residência, conforme especificado nos critérios de inclusão, de forma aleatória. Após esse levantamento foi enviado um like (forma do aplicativo usada para informar interesse pela pessoa) e aguardando para tentar fazer um match (quando a pessoa que recebeu um like corresponde, abrindo automaticamente um chat para que o casal converse). Após a ocorrência do match e a abertura do chat os pesquisadores se apresentaram aos usuários do Tinder e apresentaram a pesquisa, buscando assim captar participantes para a pesquisa. Aqueles que foram voluntários receberam um email com o link para acesso à plataforma Google Forms, onde constava o Termo de Consentimento Livre e Esclarecido (TCLE) e o questionário. O questionário foi aplicado no mês de abril e maio de 2021. Devido à forma como os dados foram coletados, utilizando a ferramenta do Google Forms, não houve qualquer constrangimento para ambas as partes, o que facilitou a coleta de dados.

Para a análise dos dados quantitativos da pesquisa, utilizou-se a estratégia estatístico- descritiva, que segundo Appolinário (2012) tem o intuito de descrever, resumir, totalizar e representar os dados que foram obtidos em uma pesquisa através de gráficos. A análise dos dados qualitativos foi conduzida por meio da análise do conteúdo temático que visa compreender o fenômeno, sem utilizar de deduções, que se baseiam nos dados da informação, que possam fazer previsões válidas sobre a realidade que ocorrerá (Appolinário, 2012).

A amostragem da pesquisa foi por acessibilidade e teve uma amostra de 30 (trinta) jovens, sendo 15 (quinze) mulheres e 15 (quinze) homens. Os participantes da pesquisa eram jovens na faixa-etária de 18 a 24 anos, usuários do aplicativo Tinder, solteiros e residiam na cidade de Manaus. Cabe ressaltar que se optou por essa faixa-etária, pois de acordo com os dados divulgados pelo Tinder, 50\% dos usuários correspondem a faixa etária de 18 a 24 anos (Dredge, 2015). Todos os participantes tiveram seus nomes substituídos por letras neste artigo para que os mesmos pudessem ser citados, sem que houvesse qualquer exposição, respeitando assim a confidencialidade dos nomes das participantes.

É importante ressaltar que, por tratar de pesquisa com seres humanos, foram respeitadas todas as medidas estabelecidas na Resolução no 466/2012 do Conselho Nacional de Saúde, sendo seguidos todos os aspectos éticos pertinentes. Esta pesquisa foi aprovada pelo Cep, conforme CAAE $n^{\circ} 40502120.2 .0000 .5020$ e parecer $n^{\circ} 4.603 .388$, de 21 de março de 2021.

\section{Resultados e Discussão}

A seguir serão apresentados os achados da pesquisa os quais serão confrontados com os achados das investigações de outros autores. Inicialmente serão discutidos os resultados quantitativos e na sequência, os dados qualitativos. 


\section{Gênero}

O primeiro passo da pesquisa foi levantar com qual gênero o(a) participante se identificavam. Os resultados da pesquisa mostraram que $60 \%$ dos participantes se identificavam como do gênero masculino e $40 \%$ do gênero feminino. Em uma pesquisa de 2015, feita pela Global Web Index, observou-se que o maior número de usuários (62\%) correspondia ao gênero masculino e 38\% ao gênero feminino (Dutra, 2017). Flores (2020) comenta que antes o Aplicativo Tinder tinha apenas duas opções no campo de gênero, sendo estes: homem e mulher, entretanto, com as atualizações feitas no mês de julho de 2020, o usuário passou a ter mais opções, quanto ao gênero que se identificavam e a orientação sexual, para exibir no seu perfil da plataforma.

Sobre o assunto, ainda buscou-se levantar qual o gênero que o usuário estava buscando no Tinder, verificando-se que 43,3\% dos participantes buscavam os gêneros feminino e masculino para relacionar-se, 30\% dos participantes buscavam usuários do gênero feminino para relacionar-se e 26,7\% dos participantes procuravam usuários do gênero masculino para uma relação. Não foram encontrados trabalhos que tratassem do assunto de forma especifica, observa-se que existe uma prevalência de participantes que estão abertos a relações com o gênero masculino e feminino.

\section{Motivações que levaram a utilizar o Tinder}

Quanto aos motivos que levaram o participante a utilizar o Tinder, verificou-se que 53,3\% dos participantes utilizam o Tinder por desejarem conhecer pessoas com interesses em comuns, 30\% dos jovens utilizam o aplicativo por desejarem encontros sem compromisso e/ou sexo casual, 10\% por desejarem encontrar um (a) namorado (a) e 6,7\% apenas estavam curiosos quanto à ferramenta. Apesar da diversidade de motivos, observa-se que a maioria dosa usuários desejam estabelecer relações a partir dos interesses em comum, seja para amizade, namoro ou sexo. Souza et al. (2016) comenta que o usuário do Tinder busca pessoas com interesses em comum, para não sair da sua zona de conforto. Na busca pela satisfação dos seus desejos, alguns usuários relacionam-se com pessoas que tenham interesses em comuns a fim de criar uma relação, mesmo que de forma superficial (Oliveira, Barros \& Goulart, 2016). As relações superficiais oferecem maior tranquilidade aos participantes da relação, pois evita qualquer tipo de frustração ou apego, tornando-se difícil a separação. Entretanto, Fernandes e Sena (2019) argumentam que reduzir os usuários de aplicativos de namoro ao status de 'sempre na expectativa do próximo parceiro, sem interesse de desenvolver relações sólidas' é demasiadamente generalista.

Com esse resultado surge o questionamento sobre a necessidade de se relacionar por meio de aplicativos, afinal existem mais de 10 milhões de usuários do Tinder no Brasil, sendo o terceiro aplicativo mais usado pelos jovens brasileiros, perdendo apenas para o Facebook e Instagram (Dutra, 2017).

Para melhor compreensão desse fenômeno social, fez-se necessário saber o que leva esses jovens a optar pelo Tinder, conforme veremos a seguir.

\section{Fatores que levaram os jovens a utilizar o Tinder}

Em relação aos fatores que levaram o participante a utilizar o Tinder verificou-se que 36,7\% dos participantes utilizaram o Tinder pela facilidade de conhecer pessoas que moram próximas, 23,3\% utilizaram pela maior facilidade que tem em comunicar-se virtualmente, $20 \%$ utiliza o Tinder pela influência dos amigos e $20 \%$ alegaram não saber o motivo. Reforça-se que as pessoas estão se utilizando do aplicativo para conhecer outras pessoas de forma virtual, pois o Tinder ajuda os usuários a conhecerem pessoas e a terem novas experiências, devido à facilidade de comunicação (Souza, 2016). Na maior parte das vezes quem se utiliza desse aplicativo são os jovens, conforme já constatamos anteriormente. Segundo Tosin et al. (2016) a maioria das pessoas que utilizam as redes sociais são jovens que buscam um meio de comunicação (87\%), seguido de diversão $(82 \%)$, e relacionamentos $(81 \%)$. Os indivíduos que iniciam relacionamentos virtuais, ou deixam esses relacionamentos apenas no virtual, se sentem mais seguros nessas relações (Lins, 2007). 
Neste resultado destaca-se que as relações físicas estão sendo substituídas por relações virtuais, pois a comunicação se torna mais fácil e aprazível, afinal não se tem que olhar nos olhos do outro ou demonstrar constrangimento durante uma conversa com um pretenso par amoroso. Alguns indivíduos percebem os relacionamentos virtuais como uma adaptação moderna das formas de lidar com as relações e vínculos, e apesar desses relacionamentos começarem de forma virtual não vão se consolidar através dessas ferramentas (Acselrad \& Barbosa, 2017). Costa (2005) defende que os relacionamentos virtuais que são caracterizados por Bauman como frágeis e superficiais são definidos equivocadamente, pois, são comparados aos relacionamentos 'reais' da época em que as tecnologias digitais não existiam como agora. Lins (2007 citado por Boechat, Cabral \& Souza, 2017) argumenta que tanto em relacionamentos amorosos virtuais, quanto nos reais, podem ser duradouros ou efêmeros, e os encontros virtuais geram ansiedade nos indivíduos, assim como os 'reais' também despertam medo de uma possível rejeição.

\section{Tempo que utiliza o Tinder e duração de tempo que conversa com uma pessoa virtual}

Buscando entender o tempo que os participantes utilizam o Tinder e o quanto já estão envolvidos em relações virtuais, perguntou-se aos participantes há quanto tempo eles já estavam utilizando o aplicativo e levantou-se que 36,6\% dos participantes utilizam o aplicativo há anos, $16,7 \%$ utilizam mais ou menos há um ano e 30\% utilizam a ferramenta há alguns meses e $16,7 \%$ dos participantes utilizam há algumas semanas. Observa-se nos resultados que existe um número alto de participantes que começaram a usar o aplicativo com um ano ou menos. Tal aspecto pode indicar um aumento de jovens registrados em aplicativos de namoro e amizades, reiterando a questão da necessidade dos jovens em se relacionarem virtualmente, em detrimento das relações físicas. Para Boechat, Cabral e Souza (2017) o uso das ferramentas digitais modifica a comunicação e interação no âmbito familiar e extrafamiliar. Entretanto, Groth, Ferraboli e Oliveira (2011) argumentam que a comunicação que ocorre através das redes sociais possibilita que os indivíduos estejam sempre em interação com o outro, estabelecendo seus laços sociais mesmo que seja por meio de ferramentas digitais. O Tinder possui um leque ainda maior de possibilidades de conhecer pessoas. A proposta deste aplicativo é criar combinações de pares para namoro, seja algo casual ou amizade, variando do interesse de cada um. Groth, Ferraboli e Oliveira (2011) destacam que a comunicação à distância é uma forma fácil de se comunicar e tratar certas questões, pois o indivíduo não se sente constrangido em tratar situações que não conseguiria pessoalmente.

Outro ponto levantado na pesquisa foi o tempo que o participante se relacionava com outra pessoa no Tinder. Ao se verificar o tempo que os participantes se relacionavam com outra pessoa no Tinder buscou-se levantar se as relações pelo Tinder tinham maior durabilidade, pois esses jovens passam um longo tempo utilizando e interagindo com outras pessoas pelo aplicativo. Nos resultados verifica-se que 36,7\% dos participantes costumam conversar pelo aplicativo por algumas horas, $33,3 \%$ conversam por meses, $26,7 \%$ conversam durante poucos dias e 3,3\% conversa até encontrar outra pessoa interessante. Nos resultados evidencia-se que as relações, na maior parte das vezes, são efêmeras. Bauman (2004 citado por Souza, 2019) argumenta que o maior prazer do indivíduo moderno está na busca em alcançar o prazer. A partir do momento que o objeto de desejo é alcançado, o indivíduo perde interesse e procura um novo objeto, se empenhando na busca de alcançar este, nunca saindo do ciclo infinito de querer- desejar - alcançar - querer. Reis e Almeida (2018) ressaltam que há falta de paciência para investir, não há mais tempo para planos e projeto e o "agora" deve ser imediato e preciso, e quando entediados ou sem interesse em prolongar conversas, esses indivíduos simplesmente desistem de estabelecer algum vínculo ou acham outras pessoas para conversar.

A partir dos dados obtidos e levando em conta a discussão realizada, entende-se que a maioria dos indivíduos que participaram da pesquisa utilizam a ferramenta há alguns anos, e está é uma forma de conhecer pessoas ao longo do tempo, mesmo que essas conversas possam durar algumas horas, alguns meses ou até encontrar alguém que este ache mais 
interessante e isso se deve a forma que as relações estão se tornando mais distantes e superficiais, não por culpa de ferramentas digitais que permitem mais comunicação, mas pela forma que os indivíduos estão lidando e interagindo entre si. Aplicativos como o Tinder permitem apenas que este tenha mais possibilidades de encontrar seus objetivos.

\section{A evolução dos relacionamentos amorosos pelo Tinder}

Quanto aos relacionamentos amorosos fora do contexto virtual verificou-se que 36,7\% dos participantes não começam um relacionamento amoroso, limitando-se a encontros, 26,7\% não levam tão a sério os relacionamentos que começam pelo Tinder, 23,3\% dos participantes tem relacionamentos físicos satisfatórios e duradouros e 13,4\% dos participantes não se envolvem, pois não querem se decepcionar, por precaução ou por já terem se decepcionado. Os resultados evidenciam que Almeida et al. (2015) comentam que os relacionamentos contemporâneos tendem a não serem duradouros, devido aos sentimentos ruins que permanecem do relacionamento anterior, que geram ansiedade, e esses indivíduos acabam entrando em novos relacionamentos com esses sentimentos negativos. Os mesmos autores ainda comentam que a ansiedade por antecipação faz com que os indivíduos evoquem antigos sentimentos, podendo repetir os mesmos erros nos relacionamentos posteriores.

O relacionamento real pode gerar ansiedade e ser, nas palavras da Participante J "Saber sair do chat pra vida real é um pouco desafiador". Bauman (2004) argumenta que quando o relacionamento sai do virtual para o "real", tornam-se mais complicados de lidar, devido a existência das emoções que precisam ser enfrentadas. No virtual, torna-se mais fácil de lidar, devido a existência do botão de "deletar". Já os relacionamentos 'reais' contemporâneos são caracterizados pela efemeridade, devido à busca da satisfação imediata dos desejos, como já foi dito anteriormente, e pelo medo de sofrer ou se frustrar as expectativas da relação (Rodrigues \& Fernandes, 2017). Os mesmos autores ainda comentam que o amor romântico está ligado à percepção do incondicional, uma paixão elevada e quando se depara com a realidade uma vez, o indivíduo se frustra e a partir desse momento carrega esse medo, ou simplesmente utiliza de exemplo relações que não deram certo como base para procurar um possível relacionamento amoroso.

Esse fenômeno social de o indivíduo ter medo de se expor ao outro é entendido por Reis e Almeida (2018) como uma vivência no mundo líquido, que faz com que o indivíduo desenvolva essa "identidade líquida" de se relacionar, se tornando mais cauteloso em relação aos seus sentimentos. Entretanto, essa cautela é apenas uma armadura para não se machucar com possíveis desilusões. Pode-se relacionar os breves relacionamentos à incessante busca pelo parceiro ideal, esse desejo de encontrar alguém que o complete, faz com que os indivíduos desfazem as relações existentes para seguir até a procura (Rodrigues \& Fernandes, 2017).

Nos relacionamentos que permanecem apenas virtualmente, a característica marcante é a relação acorporal, destaca-se também a ilusão de proximidade, intimidade e a fuga da realidade, essa dualidade de mundos é criada simultaneamente para dar sentido ao mundo em que existe (Pereira \& Coelho, 2011). Essas relações são vistas como fantasias, pois a tela que se abre para o 'virtual' deixa a 'realidade' suspensa por algum tempo, o indivíduo tenta preencher os furos da realidade, tenta satisfazer seu desejo (Lemos, 2011). Entretanto, Castro (2017) considera que as interações virtuais possuem uma natureza mais desinibida, tornando mais fácil expressar os sentimentos em uma relação, principalmente em trocas de mensagem. Aplicativos de relacionamento, seja o Tinder ou qualquer outro, possibilitam que indivíduos que não se sentem seguros em conhecer pessoas ou em se expressar, tenham a oportunidade de ampliar seu ciclo social ou de adentrar num relacionamento amoroso.

\section{Como estes jovens definem sua personalidade}

Quanto a personalidade dos jovens que usam o Tinder, os participantes se definiram da seguinte forma: 53,3\% consideram ter uma personalidade extrovertida e $46,7 \%$ dos participantes se consideram ter uma personalidade introvertida. Mostra-se um equilíbrio nessa autopercepção da personalidade, entretanto deve-se considerar que o mundo virtual oferece aos seus usuários a possibilidade de serem outras pessoas, com características e personalidades diferentes daquelas que realmente 
possuem, como afirma Portella (2015) ao comentar que muitos usuários do Tinder constroem alteregos, com personalidades diferentes das suas, para chamar mais atenção de outros indivíduos que estão no aplicativos.

Giardelli (2016) comenta que na era digital, é comum que os usuários criem identidades e personalidades imaginárias, que nem sempre corresponde com a realidade, fazendo o mundo virtual tornar-se um palco, na qual tímidos tornam-se extrovertidos, e transforma o rude em romântico, criando uma vida paralela. Essa realidade paralela que esses jovens acabam criando muitas vezes é um bloqueio na hora prática de agir na vida real, pois ao mesmo tempo em que o indivíduo age com essa personalidade criada por ele mesmo no mundo virtual, ele fica em crise por não conseguir transpassar isso para o mundo real, quando chega o momento.

Principalmente quando os relacionamentos começam no mundo virtual e a outra pessoa conhece e se acostuma com as características que o outro criou virtualmente e no momento que eles trazem essa relação para o mundo real gera certa desilusão, prejudicando tanto a pessoa que foi manipulada, quanto à pessoa que manipulou e mentiu sobre si mesma. Santos (2017) ressalta que a internet trouxe essa nova realidade onde o mundo virtual pode ser "similar" ao mundo real, onde as pessoas muitas vezes passam a ter uma personalidade diferente quando estão no mundo virtual, sendo este um universo de possibilidades, onde muitos jovens se aproveitam dessa possibilidade de criar uma realidade imaginária sobre si mesmo, pois não se considera interessante o suficiente para trazer sua realidade ao mundo virtual.

Essa ilusão que esses jovens criam trazem diversas problemáticas que levam eles a se perderem do seu próprio eu. Dutra (2018) comenta que as pessoas que utilizam essa ferramenta virtual optam por mostrar aquilo que devem ou não partilhar, sempre levando em consideração, qual a imagem que querem transmitir ao outro, se moldando com essa realidade criada e como consequência disso acaba manipulando a sua auto apresentação. Essa mistura do que é "real" e o que é "criado" se mistura de uma forma que o próprio indivíduo não sabe em que realidade acreditar. O indivíduo segundo Boyd (2010 citado por Dutra, 2018) quer corresponder às expectativas imaginadas e criadas dos outros usuários do aplicativo, ele quer aceitação não só do outro como aceitação de si mesmo, pois tudo que ele cria de irreal no mundo virtual é o desejo dele de ser e pertencer.

\section{Como os jovens se veem em um relacionamento}

Neste tópico buscou-se entender como os participantes se entendiam em um relacionamento. Após análise, as respostas foram classificadas em três temas: insegurança na relação, expressa muito os sentimentos e o desinteresse em relacionamentos amorosos. A seguir abordaremos separadamente cada um dos temas.

\section{A insegurança na relação}

A insegurança foi identificada na fala de dez participantes. A insegurança é percebida em muitos jovens e adolescentes quando o assunto é relacionamento. Tal situação pode ocorrer em face de uma ansiedade social ou baixa autoestima, provenientes de algumas questões psicológicas ou vivencia frustrantes anteriores. Observa-se a questão da insegurança na relação quando o Participante A diz que "[...] não tenho muita confiança e isso dificulta formar vínculos novos e duradouros é muito difícil eu conseguir gostar de alguém [...]" e na fala do Participante R ao comentar como "Incerto. Parece que todos os meus sentimentos entram em conflito ao mesmo tempo."

Picinini e Bavaresco (2013) pontuam que por trás dessas ferramentas digitais cria-se uma falsa segurança de que está fora de perigos que permeiam um relacionamento real, por este motivo pessoas que se definem como inseguras quando o assunto é relacionamento, reconhecem o aplicativo de relacionamento como um refúgio para não sofrer os impactos da realidade, de um relacionamento normal. $\mathrm{O}$ indivíduo busca frequentemente preencher lacunas em sua vida, assim recorrem a notícias, informações, conversas vazias, mas carecem de perguntas referentes a si mesmos. Quando não conseguem preencher esse vazio, recorrem então a objetos externos, objetos esses que vão ocupar um espaço dentro de si (Gomes \& Teixeira, 2019). 
Essa insegurança faz com que muitos jovens fiquem receoso de entrar na relação ao como o Participante D disse "Fico mais na defensiva, lutando contra todos os sentimentos que a insegura me possibilita." Lindholm (1998, citado por Costa, 2005) define que nas sociedades líquidas" as pessoas se sentem vulneráveis, pois sentem falta de grupos ou laços primários, onde essa insegurança promove a busca por um amor intenso capaz de dar algum sentido mesmo que temporário à sua existência. Tannus (2018) afirma que encontrar o "par ideal" dentre as promessas contemporâneas é a mais desejada para chegar à felicidade, afirmação exaltada em livros e filmes, onde consequentemente transmite esse anseio para o indivíduo, o desejo de concretizar um relacionamento.

A respeito do amor romântico, Illouz (2005, citado por Costa, 2005) afirma a indústria os filmes românticos buscam associar o relacionamento à realização existencial e ao sucesso pessoal, ou seja, para que o indivíduo seja, de fato, realizado na vida deve ter um "amor romântico". Entretanto, essa falsa ideia da relação de felicidade e amor leva o indivíduo a criar cenários imaginários e fantasiosos, iludindo-se a si mesmo (Souza, 2019) e, por vezes, o impedindo de buscar sua felicidade entendendo que o amor é um componente desse estado de humor. Esses devaneios raramente correspondem com a realidade, sendo ideias frustradas, mas que existem para chegar perto do prazer sonhado, apesar de efêmero.

A partir da discussão verifica-se que a insegurança na relação é uma característica natural em cada indivíduo, no entanto, ela se transforma em sofrimento se o indivíduo não enfrenta essa dificuldade cedo e decide, permanecendo em sua zona de conforto, como foi observado nas falas dos participantes.

\section{Demonstra muito os sentimentos}

Demonstrar seus sentimentos de forma verdadeira foi como 12 participantes se percebem em uma relação. O sentimentalismo pode estar associado a ser emotivo ou a excesso de emoções. Entende-se que parte do universo de jovens que utiliza o Tinder ainda tem o desejo de encontrar um grande amor e se apaixonar e expressam isso com a demonstração de seus sentimentos, ou seja, o sentimentalismo exerce uma forte influência nesses jovens, conforme se observa nas falas abaixo:

Sou muito carinhosa, gosto de estar perto sempre que possível, quer seja de maneira física ou virtual. Gosto de me conectar com quem estou me relacionando [...] Sempre que posso, tento agradar. (Participante C).

Acho que sou muito sentimental, mas não sei bem como expressar isso e acaba soando um pouco apegada demais. (Participante L).

Sentimental, um pouco até demais. Acho que por isso as coisas não dão certo, eu me apego demais [...]. (Participante I).

De acordo com Lipovetsky (1983) o sentimentalismo sofreu o mesmo destino que a morte, pois este se torna incomodo quando é expresso, o autor faz a comparação com a morte por ser vista como rançosa, e que para ser afetuoso tem que ser discreto. Alguns dos participantes se definiram como sentimentais, mas relatam que o sentimentalismo, o apego e o romantismo, acabam prejudicando o relacionamento. Tal entendimento é valido somente quando somente uma parte tem esse sentimento, o que não é comum no ambiente do Tinder.

Rodrigues e Chalhub (2010) argumentam que expressar sentimentos pode deixar de ser algo saudável e se tornar problemático quando o indivíduo não tem sua própria autonomia e passa a exigir do outro, formas de demonstrar sentimentos na mesma proporção exacerbada. Para Tannus (2018) o romantismo cria a idealização de um relacionamento plenamente feliz, onde após essa concretização é chegado ao fim da não desejada solidão. Costa (2005) define também que na modernidade tardia o amor romântico é idealizado com forte influência cultural, postula também que como idealização o amor romântico promete ao indivíduo o conhecimento pleno de sua própria singularidade, por parte dessa influência cultural. 


\section{Desinteresse em relacionamentos amorosos}

$\mathrm{O}$ desinteresse em relacionamentos amorosos foi encontrado na fala de oito participantes. O desinteresse em relacionamentos pode se dá por diversos fatores, seja pela falta de interesse ou por motivos que alguns autores pontuam estar ligada a laços e a dificuldade em mantê-los ou aprofundamento das relações. O Participante G afirma que "Prefiro não ter relacionamentos amorosos, só casualidades." E do Participante B ao comentar que "Ultimamente tenho estado sem interesse em relacionamentos (amorosos) diferente de anos anteriores". O desinteresse em relacionamentos, de acordo Fernandes e Sena (2019), ocorre pela morte do amor romântico e a emergência de uma prática afetiva mais efêmera e líquida.

Em sua resposta o Participante F apresenta uma condicionante para que haja interesse "Quero distância, a pessoa tem que ser muito incrível e inteligente para eu ter interesse." Esse comentário estabelece critérios do outro para que ele tivesse interesse ou para justificar a sua própria falta de interesse. Esta forma de agir se encaixa no chamado "amor líquido". Para Bauman (2004) as relações contemporâneas aparecem e desaparecem em uma velocidade instantânea. Os indivíduos da modernidade líquida são incapazes de quaisquer sustentos que envolvam os laços com os outros, pois tratam seus parceiros amorosos como mercadorias a serem consumidas e descartadas após o uso (Bonavitta, 2015; Fernandes \& Sena, 2019).

\section{Expectativas ao utilizar o Tinder}

Este tópico buscou compreender as expectativas dos participantes com relação ao uso do Tinder. Com a análise das respostas levantou-se as temáticas: A existência de relações superficiais, as relações a longo prazo e os interesses em comum.

\section{A existência de relações superficiais (ou rasas)}

Relações superficiais foi estabelecida nas falas de quinze participantes, que relataram suas experiências, expectativas e frustrações, que estão ligadas aos usuários que conheceram no aplicativo. Para Kopytoff (2008 citado por Souza, 2016) o problema não está no aplicativo, mas nas interações dos próprios usuários, pois cada um tem seus objetivos ao utilizar a plataforma. Essa relações superficiais podem ser identificadas na fala do Participante $\mathrm{K}$ ao comentar que "[...] geralmente as pessoas só procuram diversão passageira e casual."e na fala do Participante $\mathrm{G}$ ao dizer que “[...] Mesmo com os matches, as pessoas raramente demonstram interesse em avançar uma conversa ou até mesmo em estabelecer tal." A superficialidade das relações foi observada na fala do Participante X ao desabafar "Vazias. A maioria utiliza o Tinder em busca de aparências não vejo como isso pode ser se não vazias, tentando preencher seu tempo com rolos que não vai levar a lugar nenhum.”

A existência de uma perda de relacionamentos mais sérios, mantendo-se de forma superficial e passageira emerge a concepção de uma despreocupação com os sentimentos do outro, podendo causar frustração quando essa "relação rasa" não for de comum acordo. Castro (2014 citado por Fernandes \& Sena, 2019) comenta que o individualismo e o consumismo exacerbados são frutos da modernidade líquida, se manifestam nos aplicativos de relacionamentos, condicionando seus usuários a usar uns aos outros, focando em prazeres momentâneos e a ideia do amor romântico não tem mais espaço no cenário atual. A fala do Participante E espelha bem essa ideia quando ele diz "Eu, particularmente, nunca almejei algo sério no aplicativo uso mais como passa tempo[...]".

Maia e Bianchi (2014) consideram que o uso de aplicativos de paquera pode desenvolver laços sociais. Essas ferramentas são grandes aliadas no desenvolvimento de vínculos afetivos seja para amizade, encontros casuais ou namoro. Entretanto, a superficialidade das relações estaria ainda ligada a questões de insegurança do próprio indivíduo que ao sair da relação virtual e partir para algo real (físico) cria um receio de não atender as expectativas que ele mesmo impôs ao parceiro, preferindo manter a relação rasa a fim de não decepcionar o outro e também não se decepcionar. 
Tal entendimento é explanado por Bauman (2004) ao pontuar que as relações atuais são menos frequentes e duradouras, devido ao estado de liquidez social, ou seja, o indivíduo da sociedade líquida se sente inseguro e com medo de se relacionar. O indivíduo, apesar de sentir um forte desejo de estreitar seus laços, ao mesmo tempo sente a necessidade de mantêlos frouxos. Dessa forma, mesmo que os relacionamentos se iniciem seja no virtual ou no presencial, o que vai determinar que estes relacionamentos não sejam efêmeros são as intenções de cada indivíduo.

Diferente de Narciso, o usuário não fica limitado apenas a si mesmo, ele investe seu tempo no outro e em si mesmo, ampliando novos laços, que podem se tornar duradouros ou frágeis dependendo do objetivo que o usuário procura, mas terá essa possibilidade de conhecer um número maior de pessoas que normalmente conheceria.

\section{Relações a longo prazo}

O tema "As relações a longo prazo" foi observado na fala de oito participantes. Essas relações, que podem ser sociais ou amorosas, foram iniciadas pelo aplicativo Tinder e se fortaleceram com o tempo. Os laços sociais podem ser fortes ou fracos, o que dependerá da quantidade de tempo, intensidade emocional, intimidade e serviços recíprocos que caracterizam um laço (Granovetter, 1973 citado por Recuero, 2009). As expectativas de relações longínquas e satisfatórias que fujam da superficialidade, são percebidas nas falas da Participante A ao comentar que "Conheci algumas pessoas legais no Tinder [...] tem uma pessoa que se tornou um grande amigo, faz praticamente um ano que nos conhecemos." e no trecho da fala do Participante $\mathrm{S}$ ao dizer que "[...] consegui conhecer muitas pessoas legais, criando amizades profundas."

As relações a longo prazo, sejam amizades ou namoros, se constituem através dos laços fortes, dito anteriormente, que se caracterizam pela intimidade, proximidade e intencionalidade em criar e manter essa conexão com o outro. Já os laços fracos são as relações esparsas que não se aprofundam, na qual as trocas sociais são difusas (Granovetter, 1973 citado por Recuero, 2009).

Os usuários do Tinder que buscam relações românticas acabam se decepcionando quando utilizam o aplicativo e encontram pessoas que não buscam o mesmo objetivo de estreitar os laços. Segundo Santos (2017), a falta de paciência em conhecer o outro verdadeiramente, seja no virtual ou real, é o que impede de os relacionamentos se tornarem duradouros. Utilizar o Tinder e dá o primeiro match não é garantia de que esta pessoa é adequada, relacionamentos fortes se constituem com o tempo e romances não são construídos de um dia para a noite no primeiro ou segundo match.

Branden (1982 citado por Fernandes \& Sena, 2019) propõe pensar no amor romântico a partir de vetores ligados, como a intimidade, vulnerabilidade e o envolvimento de uma ligação emocional intensa, criar laços. Em síntese, o amor romântico é entendido como um vínculo passional espiritual-emocional-sexual. Entretanto, os resultados da pesquisa inferem uma perda ou redução das relações longas e a busca do amor. Esse fenômeno social é explicado por Fernandes e Sena (2019) ao comentarem que o amor romântico morreu devido à função exacerbada do individualismo e do consumismo, ambos são vetores da fragmentação social e das relações frágeis. Em seu livro "'amor líquido" Bauman (2004) argumenta que os homens e mulheres, são indivíduos desesperados, que tiveram seus sentimentos descartáveis, e anseiam pela segurança de relacionamentos que sejam duráveis, porém, ao mesmo tempo não estão dispostos a correr tal risco, ou seja, relacionar-se.

\section{Interesses em comum}

O tema "Interesses em comum" foi observado na fala de sete participantes. Ter interesses em comum com outra pessoa facilita a criação de um vínculo, por isso é natural o indivíduo procurar essa forma de ligação com o outro, para que assim seja possível manter uma relação. A busca desses interesses em comum pode ser frustrada quando procurado em um aplicativo de relacionamento, onde não se conhece realmente com quem está se comunicando. A busca pelos mesmos interesses é demonstrada na fala do Participante $\mathrm{N}$ ao comentar que "Eu esperava conhecer pessoas interessantes e de fora do 
meu círculo social, com interesses semelhantes.", na fala do Participante $\mathrm{P}$ ao comentar "[...] apenas conhecer pessoas novas [...] com interesses iguais[...]" "e na fala do Participante Y quando comenta "Encontrar pessoas legais, com gostos parecidos."

Prado (2004 citado por Picinini \& Bavaresco, 2013) afirma que indivíduos que usam sites de relacionamentos buscam alguém com o perfil semelhante ao seu e as mesmas motivações. Os usurários do Tinder se identificam com os outros usuários que tem o mesmo perfil de afinidade que o seu e que compartilham dos mesmos interesses e gostos em comuns (Picinini \& Bavaresco, 2013). Essa associação de comparação de perfis é exatamente o propósito do aplicativo que é selecionar pessoas que você tem mais afinidade e a biografia servem para descobrir quais são os usuários que têm gostos em comuns para formar um vínculo, se este vínculo será forte ou não, vai depender de cada um (Constantino, 2015).

De acordo com Oliveira et al. (2016) com o uso desses aplicativos ou redes sociais é possível estabelecer relação entre indivíduos que tem a mesma afinidade ou objetivos em comuns. Friedrich (2017) em sua pesquisa sobre a "mercantilização dos relacionamentos" ressalta que os fatores que influenciam nos matches são influenciados por questões como aparência, localização geográfica, interesses em comuns que pode ser decisivo para um futuro relacionamento. As pessoas que utilizam aplicativos de namoro tem essa vontade de aprovação, já que o aplicativo rastreia automaticamente outros usuários que atendam essas qualificações que o indivíduo busca em uma pessoa na qual considera mais interessante para um relacionamento (Constantino, 2015).

\section{Participantes que tiveram relacionamentos que começaram pelo Tinder}

Buscando levantar experiencias de relações anteriores surgidas do aplicativo, perguntou-se aos participantes que tiveram experiências amorosas pelo Tinder a sua percepção dessa relação. Ressalta-se que esta pergunta foi direcionada apenas aos participantes que já haviam vivenciado um relacionamento amoroso anterior, iniciado no Tinder, limitando ao número de 17 (dezessete) participantes. Com a análise dos resultados obteve-se duas temáticas a serem discutidas: O surgimento de uma amizade e bom relacionamento e as Relações vazias e superficiais, as quais serão discutidas a seguir.

\section{O surgimento de uma amizade e bom relacionamento}

Esta temática abordou o surgimento de amizades e relacionamentos satisfatórios após a relação dos participantes. Alguns usuários tiveram relacionamentos, que se iniciaram pelo Tinder, que foram breves, mas foram bons o que reforça os argumentos de alguns autores, visto anteriormente, que essa ferramenta pode ajudar os usuários a estabelecerem laços e que os mesmos podem ser fortes ou fracos, de acordo com os próprios usuários. Observemos as falas dos participantes:

\footnotetext{
"Meu primeiro relacionamento amoroso foi através de um match no Tinder. A relação foi rápida, durou alguns poucos meses [...] foi um bom relacionamento apesar da imaturidade de ambos os lados. Hoje mantemos a amizade." (Participante A).

"Eu conheci uma menina no Tinder com quem eu acabei namorando. Nosso relacionamento foi um pouco curto [...] foi extremamente satisfatório e uma experiência incrivel de duas pessoas se conhecendo melhor." (Participante E).
}

"Foi bom enquanto durou, mas não é algo que eu provavelmente faria de novo". (Participante J).

É importante notar que apesar desses participantes exporem que não foram relacionamentos que duraram, mesmo assim afirmaram que tiveram uma boa experiência durante o relacionamento de forma satisfatória. Em contrapartida, essa característica citada na fala dos participantes da pesquisa só confirma ainda mais o que Bauman (2004) cita sobre serem relações de vínculos frágeis, relações efêmeras. Esses relacionamentos são construídos em cima de insegurança e medo, pois eles querem se relacionar, mas ao mesmo tempo tem medo de estabelecer essa relação. E muitas vezes não tem paciência para lidar com os conflitos que ocorrem dentro de um relacionamento. 
De acordo com Smeha e Oliveira (2013) os relacionamentos amorosos da contemporaneidade são caracterizados como relacionamentos com menor tolerância aos conflitos, menos paciência e mais imediatismo por isso muitas vezes são relacionamentos momentâneos, sem durabilidade. Ribeiro (2010 citado por Smeha \& Oliveira, 2013) em sua pesquisa, pontuam que os relacionamentos podem dá errado devido ao medo da mudança que ocorre na vida desses jovens, eles passam a assumir maior responsabilidade, eles podem se magoar ou acabar magoando o outro. Frente a essa responsabilidade, Costa (1998 apud Smeha \& Oliveira, 2013) comenta que o indivíduo para se proteger das inseguranças e medo utilizariam da estratégia psicológica chamada flutuação, que se caracteriza por ser uma ação anestésica em relação a uma situação causadora de medo.

A categoria Amizade sólida foi observada na fala de sete participantes, que relatam terem conseguido construir uma amizade duradoura através do Tinder, reforçando a ideia de que no aplicativo, amizades podem ser construídas. Essa categoria foi observada na fala do Participante F ao afirmar que "Conheci uma pessoa que por anos foi uma amizade virtual mas, que se tornou amiga até os dias de hoje. Relação de amizade mais sólida" e na fala do Participante $S$ ao comentar que "Tenho um grande amigo que nos conhecemos pelo Tinder, ele ainda está em busca de namoradas, mas nosso relacionamento é de amizade. Alguns acham que vão encontrar a pessoa ideal lá, mas às vezes encontra um amigo, que pra mim é melhor do que relacionamento amoroso".

Sousa e Santos (2011) consideram que os relacionamentos de amizade têm a função de promover afeto, intimidade e confiança gerando um grande impacto saudável para a vida do indivíduo, principalmente quando a amizade é sólida. A experiência de amor e afeto proveniente das relações de amizade é única no ciclo vital. Ainda ressalta que ter uma boa amizade pode fazer com que a pessoa se sinta mais aceita, compreendida e confiante, fatores que a amizade oferece que muitas vezes são mais eficazes do que um relacionamento amoroso.

Apesar de ser um aplicativo de relacionamentos amorosos, muitos desses jovens, apesar de não conseguir o que planejavam (um relacionamento amoroso), acabam cativando uma amizade de forma positiva. Esse fenômeno é explicado por Sousa e Santos (2011) quando comentam que as amizades de jovens adultos são escolhidas por similaridade, sejam em instrução, classe social, interesses ou estágio do ciclo de vida familiar. Por isso, durante a procura por um parceiro amoroso, os usuários podem se deparar com pessoas que não se tornam um parceiro, mas se torna um amigo.

\section{Relações vazias e superficiais}

As relações vazias e superficiais foram apresentadas na fala de 7 participantes. Como já observado em questões anteriores, a efemeridade e superficialidade das relações foi uma característica debatida por alguns participantes. As relações descritas como momentâneas não são consideradas proveitosas e construtivas, gerando, por vezes, frustrações e ansiedades na vida de um indivíduo. Essa frustração é observada na fala do participante $\mathrm{Z}$ ao comentar que "Nunca funcionou, sempre ficou no sexo, ou em uma conversa que durou algumas horas" e do Participante G ao comentar que sua relação foi "Fútil, não éramos compatíveis."

Bauman (2004) postula que esses relacionamentos virtuais podem ser desmanchados com mais facilidade, pois não são construídos de forma sólida. Oliveira et al. (2016) também observa que essas novas tecnologias tem o poder de conectar um grande número de indivíduos, no entanto esses laços estão em um ambiente raso sem nenhuma profundidade e sendo insuficientes para garantir uma durabilidade na interação, onde a rapidez em encontrar outras pessoas é a mesma rapidez que essas relações se desfazem, sendo de fato relações momentâneas como observado na fala dos participantes da pesquisa. Essa é a característica do indivíduo da sociedade líquida, suas conexões com os outros é intensa e breve (Oliveira, Barros \& Goulart, 2016). 
As relações virtuais quando passadas para a realidade física podem gerar uma frustração, limitando essa relação a uma "amizade rasa" sem qualquer aproximação maior. Reforçando a ideia de que os usuários do Tinder não precisam se mostrar como realmente são, adotam alteregos para atrair mais pretensos parceiros. Nas falas a seguir verifica-se que as relações que tiveram através do aplicativo foram fúteis e que gerou dor de cabeça. Algumas ainda se mostraram superficiais e com pouco conteúdo, tornando-se efêmeras, conforme verifica-se na fala do Participante N quando comenta que "No início foi legal, mas depois se tornou apenas algo conveniente, [...]embarquei em algo superficial, que só serviu para me deixar com dor de cabeça." E quando o Participante C explica "Ambos queriam apenas algo casual, então durou alguns meses. [...] Acho que eu não estava pronto para ter algo sério de verdade."

O aplicativo fornece ao usuário um cardápio de possibilidades, mas nem sempre o primeiro match do dia será aquele que o usuário vai construir um relacionamento que posteriormente será duradouro. Bauman (2004) afirma que a rapidez em encontrar outras pessoas é a mesma rapidez que essas relações se desfazem desencadeando assim a frustração de não obter o que foi idealizado. O mesmo autor ainda comenta que esses indivíduos que buscam uma relação virtual por ter uma lista de opções onde podem escolher qual será mais satisfatória, onde nessa busca incessante acabam se decepcionando por não ter encontrado o que considera ideal.

Ranzini et al. (2016 citado por Constantino, 2018) fortifica essa ideia salientando que na auto apresentação que os usuários fazem nesses ambientes virtuais se equilibram entre um self autêntico e uma alta-promoção, dessa forma os usuários dirigem suas identidades como querem ser vistos pelos outros, muitas vezes da forma que não corresponde com a realidade, e quando estas relações passam para a realidade existe essa descoberta onde o indivíduo não é o que mostrava ser, gerando a decepção. Segundo Souza e Moreira (2016 citado por Cunha, 2018) os indivíduos se tornaram meros perfis que podem ser editados de acordo com o próprio usuário, a representação do eu se caracteriza por uma página pessoal.

Constantino (2018) salienta que o objetivo principal do Tinder é criar perfis em parte para atender o desejo de outros usuários na busca por se manter notável e mais interessante, usando uma imagem e formulando um texto para expressar suas qualidades e se tornar o mais interessante possível para que assim seja aprovado e obtenha o desejado match. No aplicativo existe uma aprovação dos usuários que visualizam os outros pretendentes, onde é feita uma análise se é possível estabelecer uma conexão com o outro.

\section{Considerações Finais}

As relações amorosas que se iniciam pelo Tinder, algumas mais duradouras que outras, são consequências do que Zygmunt Bauman denominou de "amor líquido" que tem como característica os vínculos frágeis, gerando relações efêmeras e distantes. Essas relações são construídas em cima de insegurança e medo. Esses sentimentos giram em torno da ideia de estabelecer um vínculo e ao mesmo tempo o medo de perder sua individualidade ao estabelecer essas relações. Mesmo com esses sentimentos, ainda há o desejo de relacionar-se, e é por isso que recorrem ao Tinder.

Apesar de aplicativos de namoro não serem novidades em nosso contexto atual, constatou-se que existe preconceito em relação aos usuários dessas ferramentas, que são vistos como desesperados e superficiais. Algumas das relações que se iniciam pelo Tinder costumam não se desenvolver devido à falta de compromisso do próprio usuário, que acredita que o Tinder não é um lugar onde você encontra um (a) namorado (a).

Ao realizar a coleta de dados, e conversar com indivíduos que utilizam o Tinder, notou-se que alguns acabaram de sair de um relacionamento amoroso. Estes jovens possuem grande interesse em entender os motivos que levaram suas relações a se tornarem efêmeras, muitos até mesmo se culpam, e carregam esses sentimentos para as relações seguintes, que terminam da mesma forma que as anteriores. O que permite que o Tinder seja procurado, não é apenas por ser um lugar fácil de conversar 
com pessoas que não estão em sua agenda de contatos no celular, mas pela facilidade em conhecer pessoas que moram próximas, que possuem gostos em comuns e pela vontade em se conectar.

Ao nos aprofundarmos mais no assunto, foi percebido que existem certas questões que foram abordadas anteriormente em artigos, que não correspondem tanto com o contexto social atual, os jovens de agora são diferentes dos jovens que utilizavam o Orkut ou MSN. Estes possuem essa vontade de levar o virtual para o real, as conversas que são iniciadas pelo Tinder são levadas para outros aplicativos, que são mais práticos, não existe mais o botão de deletar, existe apenas o distanciamento que vai aparecendo depois de um encontro ou dois.

Devido à forma que a pesquisa foi realizada, via internet, utilizando a ferramenta do Google Forms, não houve nenhum constrangimento do participante, o que facilitou a coleta de dados, além de ter se apresentado como uma nova ferramenta, aprovada pelo Comitê de Ética que tem como principais vantagens a capacidade de alcançar um maior número de participantes que residam em lugares distantes.

O relacionamento e a forma que a tecnologia e as mídias sociais geram impactos nas relações dos indivíduos é algo recente, visto que o fenômeno das redes sociais alcançou a população brasileira a pouco mais de uma década. Com isso, fenômenos ligados à tecnologia ainda não recebem a atenção merecida, principalmente na área acadêmica. Desta forma, existe essa necessidade de compreender como essas ferramentas digitais alteram o comportamento, a subjetividade e os relacionamentos de seus usuários. Portanto recomenda-se a continuação de pesquisas ligadas ao tema, que possuam um olhar crítico no que tange às novas configurações de relacionamento que estão avançando junto com o contexto tecnológico.

As dificuldades encontradas ao realizar esta pesquisa foram referentes à ausência de pesquisas sobre o tema em questão, principalmente no estado do Amazonas, onde apesar do aplicativo ser popular não recebe atenção em produções acadêmicas. Esta pesquisa possibilita uma fonte de consulta para trabalhos posteriores, e abordar sobre este assunto, é uma forma de amenizar comportamentos que podem acarretar problemas psicológicos, entre eles baixa autoestima, pressão, ansiedade e depressão, já que estes jovens se sentem frustrados com seus relacionamentos e acabam colocando a culpa em si mesmo e na forma em que os relacionamentos se constroem, visto que existe esse ideal romântico que tenta ser alcançado.

\section{Referências}

Acselrad, Marcio \& Barbosa, Rafaelly Rocha Lima. (2017). Amor nos tempos do Tinder: Uma análise dos relacionamentos amorosos na contemporaneidade a partir da compreensão de jovens adultos. Estud. Pesqui. Psicol., 17 (1), 161-180 http://pepsic.bvsalud.org/scielo.php?script=sci_arttext\&pid=S1808$42812017000100010 \& \operatorname{lng}=$ pt\&nrm=iso.

Almeida, Thiago. (2015). Relacionamentos amorosos: o antes, o durante... e o depois. PolBooks.

Appolinário, Fábio. (2012). Metodologia da ciência: Filosofia e prática da pesquisa. (2 $2^{\text {sd }}$.ed.) Cengage Learning.

Bauman, Zygmunt.(2004). Amor líquido: sobre a fragilidade dos laços humanos. Zahar.

Boechat, Ieda Tinoco; Cabral, Hildeliza Lacerda \& Souza, Carlos Henrique Medeiros de. (2017). Relacionamentos virtuais e família: Enlaces interculturais. Revista internacional de Folkcomunicação, 15 (35), 141-164. Recuperado de https://revistas.uepg.br/index.php/folkcom/article/view/2281.

Bonavitta, Paola. (2015). El amor en los tiempos de Tinder. Cultura representaciones soc., 10 (19), 197-210. Recuperado de: http://www.scielo.org.mx/scielo.php?script=sci_arttext\&pid=S2007-81102015000200009\&lng=es\&nrm=iso.

Cajueiro, Roberta Liana Pimentel. (2013). Manual para elaboração de trabalhos acadêmicos: guia prático do estudante. $2^{\text {nd }}$ ed. Petrópolis, RJ: Vozes.

Castro, Marília Gurgel de. (2017). O estabelecimento de relacionamentos amorosos online entre jovens adultos. Dissertação de Mestrado). Universidade de Coimbra, Coimbra, Portugal. Recuperado de https://eg.uc.pt/handle/10316/84114.

Constantino, Fernanda Angelo. (2015). Tinder: a vitrine de pessoas. Trabalho de Conclusão de Curso (Bacharelado em Comunicação Social). Universidade Federal Fluminense- UFF, Niterói.

Constantino, Fernanda Angelo. (2018). Questões identitárias no Tinder: performance de si, autenticidade e gerenciamento da impressão a partir da percepção do gênero feminino. (Dissertação de mestrado). Universidade Federal Fluminense, Niterói. 
Costa, Sérgio. (2005). Amores fáceis: Romances e consumo na modernidade tardia. Novos Estud. -CEBRAP, 73, 111-124. Recuperado de http:// www.scielo.br/scielo.php?script=sci_arttext\&pid=S0101-33002005000300008\&Ing=en\&nrm=iso.

Cunha, Ana Rita Moreira da. (2018). Estudo qualitativo sobre as experiências de um grupo de utilizadores do Tinder. (Dissertação de Mestrado). Universidade Fernando Pessoa, Porto. Recuperado de https://bdigital.ufp.pt/handle/10284/7008.

Dutra, Flora Ardenghi (2017). Selfies no Tinder: masculinidade como performance. (Dissertação de mestrado). Universidade Federal de Santa Maria, Santa Maria.

Fernandes, Ricardo \& Sena, Patrícia Rakel De Castro. (2019). O (des) interesse no amor romântico em tempos de aplicativos de paquera. Intexto. 45(1), 146163. Recuperado de https://seer.ufrgs.br/intexto/article/view/79612.

Flores, Julia. (2020) Tinder libera mais opções de gênero e orientação sexual para usuários. São Paulo. Recuperado de https://www.uol.com.br/universa/noticias/redacao/2020/06/24/Tinder-libera-mais-opcoes-de-genero-e-orientacao-sexual-para-usuarios.htm.

Friedrich, Luísa de Carvalho (2017). A mercantilização dos relacionamentos no contexto da midiatização: análise do aplicativo Tinder. Trabalho de conclusão de curso (Bacharelado em Relações Públicas) - Universidade Federal do Rio Grande do Sul, Porto Alegre. Recuperado de https://lume.ufrgs.br/handle/10183/169493.

Giardelli, Gil. (2016). Você é o que você compartilha: e-agora: como aproveitar as oportunidades de vida e trabalho na sociedade em rede. São Paulo: Editora Gente.

GIL, Antônio Carlos. Como elaborar projetos de pesquisa. (4 ${ }^{\text {th }}$ ed.) Atlas.

Gomes, Ágatha Aila Amábili de Meneses \& Teixeira, Selena Mesquita de Oliveira. (2019). Vivência do tédio em jovens: uma análise sobre os modos de subjetivação contemporâneos. Gerais, Rev. Interinst. Psicol., 12 (2), 263-281. http://pepsic.bvsalud.org/scielo.php?script=sci_arttext\&pid=S198382202019000200006 .

Groth, Carlise Inês; Ferraboli, Cynthia Raquel \& Oliveira, Lisandra Antunes de. (2011). Entre o real e o virtual: análise da sociabilidade vivenciada nos relacionamentos a distância e presenciais. Unoesc\&Ciência, 2 (1), 63-72. Recuperado de https://portalperiodicos.unoesc.edu.br/achs/article/view/143.

Lemos, Patrícia do Prado Ferreira. (2011) Navegar é fantasiar: relações virtuais e psicanálise. Psico, 42 (1), 59-66.

https://revistaseletronicas.pucrs.br/ojs/index.php/revistapsico/article/view/6454.

Lima, Nádia Laguárdia de; Moreira, Jacqueline de Oliveira; Stengel, Márcia \& Maia, Lucas Matos. (2016). As redes sociais virtuais e a dinâmica da internet. Revista interinstitucional de Psicologia, 9(1), 90-109.

Lins, Regina Navarro. (2007). A cama na varanda: arejando nossas ideias a respeito de amor e sexo: novas tendências. Best Seller.

Lipovetsky, Gilles. (2005). A Era do Vazio: ensaios sobre o individualismo contemporâneo. Manole.

Maia, João; Bianchi, Eduardo(2014). Tecnologia de geolocalização: Grindr e Scruff redes geosociais gays. Logos: Comunicação e universidade, 2 (24), 1-15. Disponível em https://www.e-publicacoes.uerj.br/index.php/logos/article/view/14157. Acesso 07 de jul. 2021.

Moura, Carolina Silva de \& Cortês, Letícia Segurado. (2015). O amor líquido na era do Tinder: uma análise da campanha publicitária do Ministério da Saúde Sob a ótica Baumaniana. In: XXXVIII Congresso Brasileiro de Ciências da Comunicação (p.1-13) Rio de Janeiro.

Oliveira, Rafael Santos de; Barros, Bruno Mello Corrêa de \& Goulart, Gil Monteiro. (2016). As tecnologias da informação e comunicação na (Des) construção das relações humanas contemporâneas: Implicações do uso do aplicativo Tinder. Revista Brasileira de Direito, 12 (1), 88-99.

Pellizzari, Bruno Henrique Miniuchu \& Barreto Junior, Irineu Francisco. (2019). Bolhas sociais e seus efeitos na sociedade da informação: Ditadura de algoritmo e entropia na internet. Rev. Direito, Governança e Novas Tec., 5(2), 57-73. https://indexlaw.org/index.php/revistadgnt/article/view/5856

Pereira, Júlio César Mendez \& Coelho, Solange. (2011). Relações sociais virtuais: uma leitura psicanalítica. (Trabalho de Conclusão de graduação). Universidade de Vale do Rio Doce - UNIVALE. Governador Valadares.

http://www.pergamum.univale.br/pergamum/tcc/Relacoessociaisvirtuaisumaleiturapsicanalitica.pdf.

Picinini, Juliane \& Bavaresco, Ângela Maria (2013). Relacionamento virtual. Psicologando, 08(1), 1-14. https://psicologado.com/abordagens/psicanalise/relacionamentovirtual.

Portella, Lauren (2015). As redes sociais digitais e o conceito de amor líquido de Zygmunt Bauman, no caso do aplicativo Tinder. (Trabalho de Conclusão de graduação). Universidade de Passo Fundo, Passo Fundo.

Prodanov, Cleber Cristiano \& Freitas, Ernani Cesar de (2013). Metodologia do trabalho científico: Métodos e Técnicas da Pesquisa e do Trabalho Acadêmico. $2^{\text {nd }}$ ed. Novo Hamburgo: Feevale.

Recuero, Raquel (2009). Redes sociais na internet. Sulina.

Reis, Fernanda Siqueira \& Almeida, Gabriela Franco de (2018). As relações líquidas contemporâneas em Bauman e Frankl: Uma discussão sobre modernidade e falta de sentido. Rev. Cient. Sem. Acad., 1 (1), 000120. Recuperado de: https://semanaacademica.com.br/artigo/relacoes-liquidas-contemporaneas-embauman-e-frankl-uma-discussao-sobre-modernidade-e-falta.

Rodrigues, Soraia \& Chalhub, Anderson (2010). Amor com dependência: um olhar sobre a teoria do apego. Psicologia.pt. 2010. Recuperado de https://www.psicologia.pt/artigos/ver_artigo_licenciatura.php?codigo=TL0155. 
Research, Society and Development, v. 10, n. 13, e318101321321, 2021

(CC BY 4.0) | ISSN 2525-3409 | DOI: http://dx.doi.org/10.33448/rsd-v10i13.21321

Santos, Alane Moreira dos (2017). Do flerte ao "match": uma breve história do aplicativo Tinder e do (s) amor (es) no Brasil. (Trabalho de Conclusão de graduação). Universidade Estadual da Paraíba, Guarabira.

Santoro, Vanessa Campos (2016). O amor nos tempos da Internet. Estud. psicanal. 1(45), 167-170.

http://pepsic.bvsalud.org/scielo.php?script=sci_arttext\&pid=S0100-34372016000100017\&lng=pt\&nrm=iso

Silva, Nelson Pedro (2004). Estudo sobre fidelidade a palavra empenhada entre os estudantes. Psicologia em Estudo, 9(2), 229-242. http://www.scielo.br/pdf/\%0DD/pe/v9n2a09.pdf.

Smeha, Luciane Naja \& Oliveira, Micheli Vieira de (2013). Os relacionamentos amorosos na contemporaneidade sob a óptica dos adultos jovens. Psicol. teor. prat. 15 (2), 33-45. Recuperado de: http://pepsic.bvsalud.org/scielo.php?script=sci_arttext\&pid=S1516-36872013000200003.

Sousa, Diogo Araújo de \& Santos, Elder Cerqueira (2011). Redes sociais e relacionamentos de amizade ao longo do ciclo vital. Rev. Psicopedag., 28 (85), 53 66. Recuperado de: http://pepsic.bvsalud.org/scielo.php?script=sci_arttext\&pid=S0103-84862011000100006.

Souza, Ana Luiza de Figueiredo (2016). Mas, afinal, o que é o Tinder? - Um estudo sobre a percepção que os usuários têm do aplicativo. Verso e Reverso, 30(75), 186-195. Recuperado de: http://revistas.unisinos.br/index.php/versoereverso/article/view/ver.2016.30.75.03.

Tannus, Ana Maria Nora (2018). Amor em tempos de banda larga: Uma análise sociológica do aplicativo Tinder. (Trabalho de conclusão de graduação). Curso de Ciências Sociais, Universidade Federal de São Paulo, São Paulo.

Tosin, Maria Gabriela; Vilela, Luísa Rocha; Petzak, Aline Sphair \& Custódio, Juliana Cândido (2016). O relacionamento do consumidor com as marcas através das redes sociais. In Anais do XVII Congresso de Ciências da comunicação na Região Sul (p. 1-15). Curitiba, PR. 